\title{
Pattern of Third Molar Impaction in Kashmiri Population
}

\author{
Altaf Hussain Chalkoo ${ }^{1}$, Bashir Ahmad Wani ${ }^{2 *}$, Shazia Maqbool ${ }^{3}$, Tauseefa Jan ${ }^{4}$, Rayees \\ Ahmad Sheikh ${ }^{5}$ \\ ${ }^{1}$ Professor and Head, Department of Oral Medicine and Radiology, Government Dental College, Srinagar, \\ India \\ ${ }^{2}$ Postgraduate Student, Department of Oral Medicine and Radiology, Government Dental College, Srinagar, \\ India \\ ${ }^{3}$ Postgraduate Student, Department of Oral Medicine and Radiology, Government Dental College, Srinagar, \\ India \\ ${ }^{4}$ Postgraduate Student, Department of Oral Medicine and Radiology, Government Dental College, Srinagar, \\ India \\ ${ }^{5}$ Postgraduate Student, Department of Oral Medicine and Radiology, Government Dental College, Srinagar, \\ India \\ *Corresponding Author: Bashir Ahmad Wani, Postgraduate Student, Department of Oral Medicine and \\ Radiology, Government Dental College, Srinagar, India.
}

\begin{abstract}
Introduction: The aim of this study was to evaluate the pattern of third molar impactions and various associated factors like age, gender, the angulation, width and the depth.

Materials and Methods: This prospective study include398 patients aged above 19 years with impacted third molars. After detailed clinical and radiological examination of each patient, the age, sex and number of impacted third molars were recorded. All the radiographs were reviewed in a dark room using an appropriate X-ray viewer to determine the pattern of impacted third molars with respect to their levels of eruption and angulations. When the third molar did not have functional occlusion with its roots fully developed, it was considered as impacted.

Results: There were 218 male (54.77\%) and 180 (45.23\%) female patients out of whom 166 had impacted maxillary third molars and 232 had impacted mandibular third molars. There were greater number of patients with impacted third molars in mandible than the maxilla with males having higher incidence. Majority of the patients presented with vertical impaction, level A and class-I in both males and females.

Conclusion: Third molar impaction is a common dental problem experienced by the people worldwide. However, currently the mechanisms causing this pathology and the rate of occurrence is not known. The differences in the rate of occurrences in impaction between different sexes vary in different age groups and among different populations. Therefore, future studies are required to evaluate the pattern and etiology behind this relatively high frequency of third molar impaction.
\end{abstract}

Keywords: horizontal impaction; impacted third molars; mesiangular impaction

\section{INTRODUCTION}

When teeth fail to develop and erupt in their proper functional location, they become impacted. The most frequently impacted teeth in oral cavity are the mandibular third molars.[1] Several studies have investigated the etiology of the third molar impaction with many factors reported as possible causes like lack of space distal to the permanent second molar, delayed third molar mineralization and early physical maturation.[2,3] Impacted third molars are often associated with pericoronitis, cystic lesions, neoplasm, root resorption and even can cause detrimental effects on adjacent second molar teeth.[4] There is a prevalence of $16.7 \%$ to $68.6 \%$ with no sexual predilection in third molar impaction.[5-7] However some studies have reported females with higher frequency than males.[8]

The aim of this study was to evaluate the pattern of third molar impactions and various associated factors like age, gender, the angulation, width and the depth in Kashmiri population. 


\section{Materials AND Methods}

This prospective study was conducted in the department of Oral Medicine and Radiology from January 2018 to April 2019 of patients who reported to the department for dental treatment. Inclusion criteria include patients with impacted third molars of above 19 years of age with complete root development. Patients with incomplete root development of third molars or missing second molars and patients from outside the Kashmir division were excluded from the study. 398 patients aged above 19 years with impacted third molars and complete root development were selected and informed consent was taken from each patient. A detailed clinical examination of each patient was done by a single examiner. All the patients were evaluated radiographically by Orthopantomography (OPG). The age, sex and number of impacted third molars were recorded.
All the OPGs were reviewed in a dark room using an appropriate X-ray viewer to determine the pattern of impacted third molars with respect to their levels of eruption and angulations. When the third molar did not have functional occlusion with its roots fully developed, it was considered as impacted.

Winter's classification was used to determine the angulation of the impacted third molar with reference to the angle formed between the intersected longitudinal axis of the second and third molars (fig. 1-3). Vertical impaction at an angle of $10^{\circ}$ to $-10^{\circ}$; Mesioangular impaction at $11^{\circ}$ to $79^{\circ}$; Horizontal impaction at $80^{\circ}$ to $100^{\circ}$ and Distoangular impaction at $-11^{\circ}$ to $-79^{\circ}$, and uncommon angulations such as Buccolingual, Mesioinverted, Distoinverted and Distohorizontal angulations were classified as 'other'.

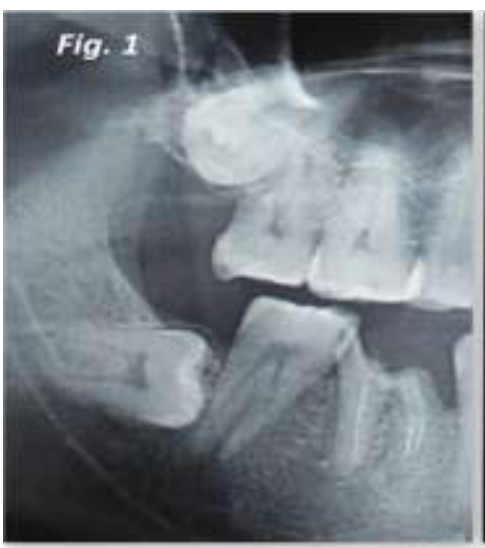

Marirontal mandibular and distoangular maxillary impaction

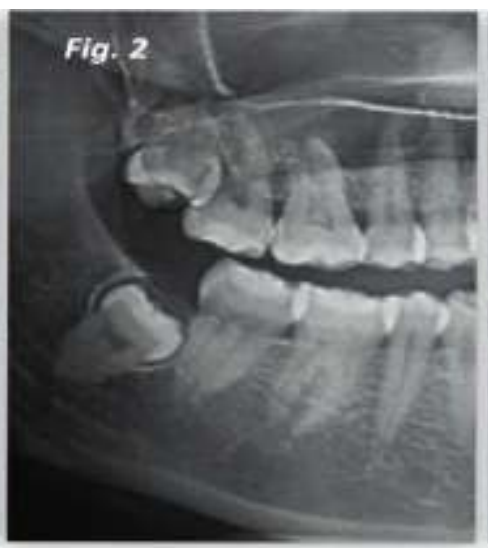

Mesioanguiar mandibular and vertical moxillary impoction

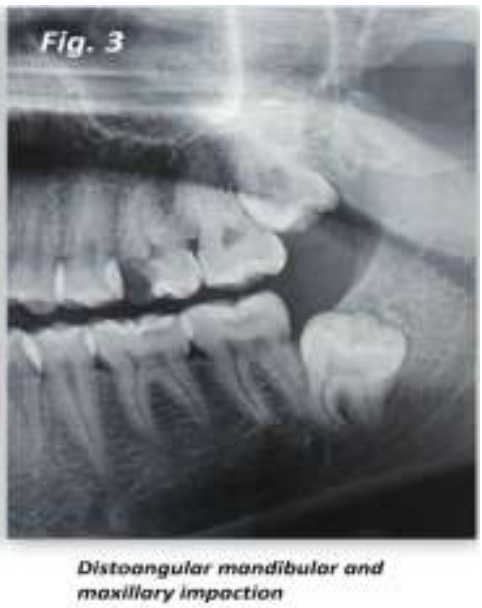

maxillary impoction

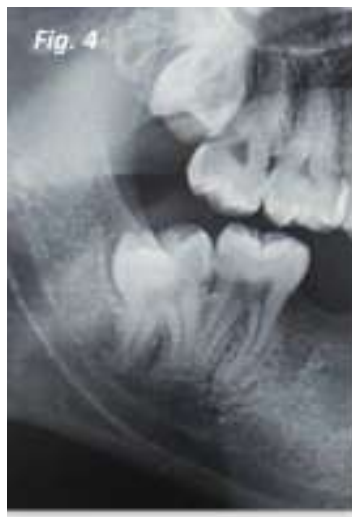

Level-A, Class-II

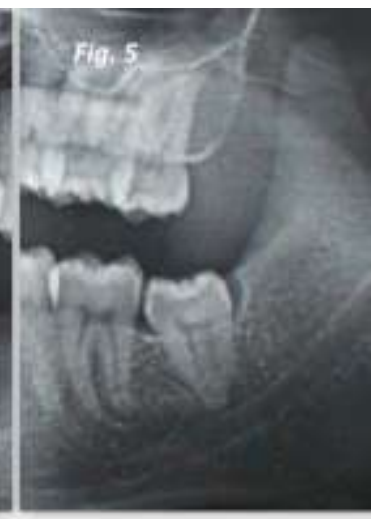

Level-B, Class-I

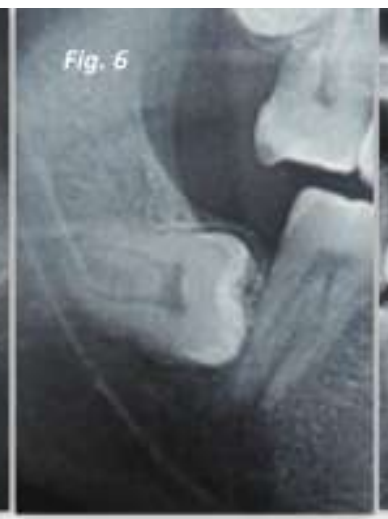

Level-C, Class-II

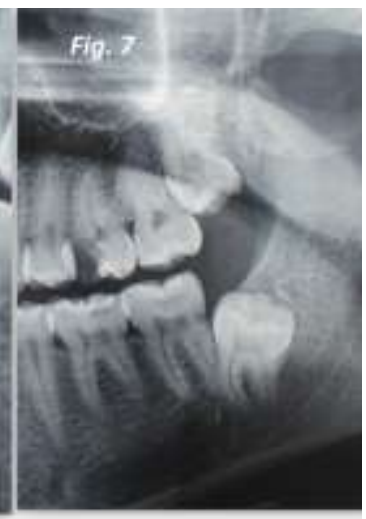

Level-B, Class-III
Pell and Gregory classification (fig. 4-7) was used to determine the level and depth of impaction as follows;

Level A- the highest portion of the impacted mandibular third molar was on a level with or above the occlusal plane,
Level B- the highest portion of the impacted mandibular third molar was below the occlusal plane but above the cervical line of the second mandibular molar.

Level C- the highest portion of the impacted mandibular third molar was below the cervical line of the second mandibular molar. 
The distance or width between the anterior border of mandibular ramus and the distal surface of the second molar was determined using Pell and Gregory classification as:

Class I: situated anterior to the anterior border of the ramus,

Class II: crown half covered by the anterior border of the ramus,

Class III: crown fully covered by the anterior border of the ramus

Statistical Methods: The recorded data was compiled and entered in a spreadsheet (Microsoft Excel) and then exported to data editor of SPSS Version 20.0 (SPSS Inc., Chicago, Illinois, USA). Data were summarized as frequency and percentage. The Pearson's Chi-squared test was used to test the association between different variables.

\section{Results}

Among 398 patients, there were 218 male $(54.77 \%)$ and $180(45.23 \%)$ female patients with impacted third molars as shown in graph-1.
Graph-1 Gender wise distribution of impacted third molars

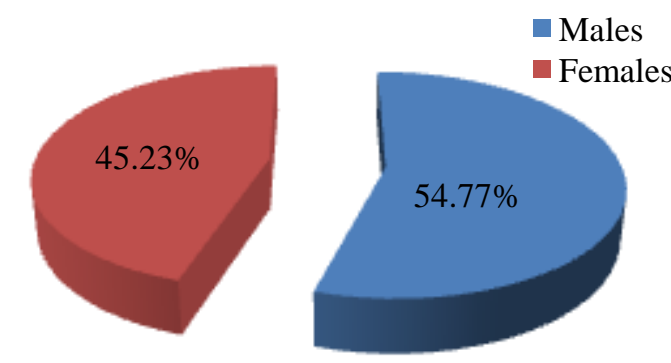

There were 166 patients with a total of 332 impacted maxillary third molars and 232 patients with a total of 464 impacted mandibular third molars as shown in table-1. There were greater number of patients with impacted third molars in mandible than the maxilla, with males having higher incidence of impacted third molars.

Table1. Distribution of impacted third molars by arch and gender $(N=796)$

\begin{tabular}{|l|l|l|l|}
\hline Gender & Maxilla & Mandible & Total \\
\hline Males & $192(24.12 \%)$ & $244(30.65 \%)$ & $436(54.77 \%)$ \\
\hline Females & $140(17.58 \%)$ & $220(27.64 \%)$ & $360(45.23 \%)$ \\
\hline Total & $332(41.71 \%)$ & $464(58.29 \%)$ & $796(100 \%)$ \\
\hline Table 2 shows distribution of the angulation of & $\begin{array}{l}\text { and females }(24.14 \%) \text {. The least incidence of } \\
\text { impacted mandibular third molars according to }\end{array}$ & $\begin{array}{l}\text { impacted mandibular third molars in males was } \\
\text { distoangular }(2.8 \%) \text { and in females was }\end{array}$ \\
Winter's classification with vertical impaction \\
showing highest incidence in both males (25\%)
\end{tabular}

Table2. Showing distribution of the angulation of impacted mandibular third molars $(N=464)$ according to winter's classification

\begin{tabular}{|l|l|l|l|}
\hline Angulation & \multicolumn{2}{|l|}{ Gender with number (n) and percentage (\%) } & Total (n \& \% ) \\
\hline & Males & Females & \\
\hline Mesioangular & $96(20.69 \%)$ & $73(15.73 \%)$ & $169(36.42 \%)$ \\
\hline Horizontal & $19(4.09 \%)$ & $17(3.66 \%)$ & $36(7.76 \%)$ \\
\hline Vertical & $116(25 \%)$ & $112(24.14 \%)$ & $228(49.14 \%)$ \\
\hline Distoangular & $13(2.80 \%)$ & $18(3.88 \%)$ & $31(6.68 \%)$ \\
\hline Total & $244(52.59 \%)$ & $220(47.41 \%)$ & $464(100 \%)$ \\
\hline
\end{tabular}

Table 3 shows distribution of the angulation of (41.57\%) and females (28.92\%). The least impacted maxillary third molars according to Winter's classification with vertical impaction showing highest incidence in both males incidence of impacted maxillary third molars was horizontal in both males $(0.60 \%)$ and females $(0 \%)$.

Table3. Showing distribution of the angulation of impacted maxillary third molars $(N=332)$ according to winter's classification

\begin{tabular}{|l|l|l|l|}
\hline Angulation & Gender with number (n) and percentage (\%) & Total (n \& \% ) \\
\hline & Males & Females & \\
\hline Mesioangular & $6(1.81 \%)$ & $24(7.23 \%)$ & $30(9.04 \%)$ \\
\hline Horizontal & $2(0.60 \%)$ & $0(0 \%)$ & $2(0.60 \%)$ \\
\hline Vertical & $138(41.57 \%)$ & $96(28.92 \%)$ & $234(70.48 \%)$ \\
\hline Distoangular & $38(11.44 \%)$ & $28(8.43 \%)$ & $66(19.88 \%)$ \\
\hline Total & $184(55.42 \%)$ & $148(44.58 \%)$ & $332(100 \%)$ \\
\hline
\end{tabular}


Among 398 patients with impacted third molars, 56 patients (112 impacted third molars) had different angulation on right and left as shown in table 4.

Table 5 shows distribution of impacted mandibular third molars by level of impaction according to Pell and Gregory classification. Majority of the patients presented with level A $(\mathrm{n}=138,29.74 \%)$ in males as well as in females $(\mathrm{n}=112,24.14 \%)$ and level $\mathrm{C}$ was the least common.

Table 4. Shows distribution of different angulation of impacted third molars on right and left

\begin{tabular}{|c|c|c|c|c|c|c|c|c|}
\hline \multirow{3}{*}{ Angulation } & \multicolumn{4}{|c|}{ Mandible $(\mathrm{n}=\mathbf{8 0})$} & \multicolumn{4}{|c|}{ Maxilla (n=32) } \\
\hline & \multicolumn{2}{|c|}{ Male } & \multicolumn{2}{|c|}{ Female } & \multicolumn{2}{|c|}{ Male } & \multicolumn{2}{|c|}{ Female } \\
\hline & Right & Left & Right & Left & Right & Left & Right & Left \\
\hline Mesioangular & 10 & 16 & 2 & 4 & 0 & 2 & 0 & 6 \\
\hline Horizontal & 6 & 2 & 4 & 0 & 0 & 2 & 0 & 0 \\
\hline Vertical & 8 & 8 & 4 & 4 & 8 & 2 & 2 & 0 \\
\hline Distal & 6 & 4 & 0 & 2 & 2 & 4 & 4 & 0 \\
\hline Total & 30 & 30 & 10 & 10 & 10 & 10 & 6 & 6 \\
\hline
\end{tabular}

Table5. Showing distribution of impacted mandibular third molars by level of impaction $(N=464)$

\begin{tabular}{|l|l|l|l|l|l|l|c|}
\hline Region & \multicolumn{3}{|c|}{ Males } & \multicolumn{3}{c|}{ Females } & Total \\
\hline & Level A & Level B & Level C & Level A & Level B & Level C & \\
\hline Right & $70(15.09 \%)$ & $32(06.90 \%)$ & $18(3.88 \%)$ & $54(11.64 \%)$ & $38(08.19 \%)$ & $18(3.88 \%)$ & $230(49.57 \%)$ \\
\hline Left & $68(14.65 \%)$ & $34(07.33 \%)$ & $20(04.31 \%)$ & $58(12.5 \%)$ & $40(08.62 \%)$ & $14(03.02 \%)$ & $234(50.4350$ \\
\hline Total & $138(29.74 \%)$ & $66(14.22 \%)$ & $38(8.19 \%)$ & $112(24.14 \%)$ & $78(16.81 \%)$ & $32(6.9 \%)$ & $464(100 \%)$ \\
\hline
\end{tabular}

The distance or width between the anterior border of mandibular ramus and the distal surface of the second molar as determined by Pell and Gregory classification. Majority of

patients presented with class-I $(\mathrm{n}=174,37.50 \%)$ in males as well as in females $(n=144,31.03 \%)$ and class-III was the least common as shown in table 6.

Table6. Showing the distance between the anterior border of mandibular ramus and the distal surface of the second molar using Pell and Gregory classification $(N=464)$

\begin{tabular}{|l|l|l|l|l|l|l|c|}
\hline Region & \multicolumn{3}{|c|}{ Males } & \multicolumn{3}{|c|}{ Females } & Total \\
\hline & Class-I & Class-II & Class-III & Class-I & Class-II & Class-III & \\
\hline Right & $86(18.53 \%)$ & $26(05.60 \%)$ & $12(02.59 \%)$ & $70(15.09 \%)$ & $30(06.47 \%)$ & $08(01.72 \%)$ & $232(50 \%)$ \\
\hline Left & $88(18.98 \%)$ & $26(05.60 \%)$ & $08(01.72 \%)$ & $74(15.95 \%)$ & $28(06.03 \%)$ & $08(01.72 \%)$ & $232(50 \%)$ \\
\hline Total & $174(37.50 \%)$ & $52(11.21 \%)$ & $20(04.31 \%)$ & $144(31.03 \%)$ & $58(12.50 \%)$ & $16(03.45 \%)$ & $464(100 \%)$ \\
\hline
\end{tabular}

\section{DISCUSSION}

Third molar impaction is a common dental problem experienced by the people worldwide. However, currently the mechanisms causing this pathology and the rate of occurrence is not known. Furthermore, the differences in the rate of occurrences in impaction between different sexes vary in different age groups and among different populations. Therefore, the first step in understanding the mechanism as well as relationship among third molar impactions is to describe the pattern of prevalence of impaction worldwide. Winter's classification measured the angle of impaction with reference to the angle formed between the intersected longitudinal axis of the second and third molars. [9] Depth or level of maxillary and mandibular third molars was classified by Pell and Gregory classification system, where the impacted teeth were assessed according to their relationship to the occlusal surface (OS) of the adjacent second molar. [10]
A Systematic Review and Meta-analysis done by K. Carter et al [11] explained geographic heterogeneity in third molar impaction frequency. They found that Middle Eastern populations with highest rates of impaction as compared to lowest rate in African populations. Asian, European and North American populations exhibited intermediate rates of third molar impaction.

In our study there were greater number of patients with impacted third molars in mandible than the maxilla with males having higher incidence of impacted third molars. There were 218 male $(54.77 \%)$ and $180(45.23 \%)$ female patients with impacted third molars. K. Carter et al found a higher rate of impaction in mandibular (mean $=25.43 \%$ ) than in maxillary $($ mean $=14.16 \%)$ third molar impactions.[11] Vertical impaction shows highest incidence in both maxilla and mandible in our study. This finding was in accordance with the studies done 
by the Reddy et al. [12] and Haideret al. [13] who also found that vertical impaction was the most common type of third molar impaction. However, Hassan AH [14] and Quek SL [15] found mesioangular impaction to be the most common type of angulation among impacted third molars.

The level and depth of impaction was determine by Pell and Gregory classification with majority of the patients having impacted mandibular third molars presented as level-A $(n=138,29.74 \%)$ in males as well as in females $(n=112,24.14 \%)$ and level-C was the least common. Samira M. Al-Anqudiet al, [16] analysing the level of impaction showed that level-A was the most common level of impaction (58\%). This disagrees with the results of other researches $[14,15,17]$ that reported level $\mathrm{B}$ as the most common level of impaction.

The distance or width between the anterior border of mandibular ramus and the distal surface of the second molar was determined by Pell and Gregory classification. We found majority of patients having impacted mandibular third molars presented with class-I $(n=174$, $37.50 \%)$ in males as well as in females $(n=144$, $31.03 \%$ ) while class-III was the least common. These findings were in accordance with the results of Monaco et al. [18] who identified the most common position as Class-I (56.2\%), while Obiechina et al. [19] from Italy, Blondeau et al. [20] from Canada and Almendros-Marques et al. [21] from Spain reported the most common position as class II (31\%).

Third molar impaction is a common dental problem experienced by the people worldwide. The differences in the rate of occurrences in impaction between different sexes vary in different age groups and among different populations. However, currently the mechanisms causing this pathology and the rate of occurrence is not known. Third molar impaction has higher incidence in the mandible than the maxilla, and vertical impaction was the most frequently seen orientation. Therefore, understanding the distribution and pattern of third molar impaction frequencies is an important first step for understanding the different etiologies of impaction as well as for clinicians in making decisions regarding treatment protocols.
The present study, lacks randomization as it was a hospital based study with small sample size. More precise studies are required in order to evaluate the impaction of third molars in a randomized sample representative of Kashmiri population.

\section{CONCLuSiON}

Third molar impaction is a common dental problem experienced by the people worldwide. However, currently the mechanisms causing this pathology and the rate of occurrence is not known. The differences in the rate of occurrences in impaction between different sexes vary in different age groups and among different populations. Therefore, future studies are required to evaluate the pattern and etiology behind this relatively high frequency of third molar impaction.

\section{REFERENCES}

[1] Dimitroulis G. A Synopsis of Minor Oral Surgery, 4th ed. Oxford, UK: ButterworthHeinemann Publishing, 1996. Pp.48-57.

[2] Ma'aita JK. Impacted third molars and associated pathology in Jordanian patients. Saudi Dent J 2000; 12:16-19.

[3] Hattab FN, Rawashdeh MA, Fahmy MS. Impaction status of third molars in Jordanian students. Oral Surg Oral Med Oral Pathol Oral RadiolEndod 1995; 79:24-9. doi: 10.1016/S1079-2104(05)80068-X.

[4] Ma'aita J, Alwrikat A. Is the mandibular third molar a risk factor for mandibular angle fracture? Oral Surg Oral Med Oral Pathol Oral RadiolEndod. 2000;89:143-6.

[5] Lima CJ, Silva LC, Melo MR, Santos JA, Santos TS. Evaluation of the agreement by examiners according to classifications of third molars.Med Oral Patol Oral Cir Bucal. 2012;17:e281-e216.

[6] Kaya GS, Aslan M, Ömezli MM, Dayi E. Some morphological features related to mandibular third molar impaction. J ClinExp Dent. 2010;2:e12-e7.

[7] Fanning EA, Moorrees CF. A comparison of permanent mandibular molar formation in Australian aborigines and Caucasoids. Arch Oral Biol. 1969;14:999-1006.

[8] Hugoson A, Kugelberg CF. The prevalence of third molars in a Swedish population. An epidemiological study.Community Dent Health. 1988;5:121-38.

[9] Winter GB. The principles of exodontia as applied to the impacted third molars: A complete treatise on the operative technic with clinical diagnoses and radiographic 
interpretations. St. Louis, Missouri: American Medical Book Co., 1926.

[10] Pell GJ, Gregory GT. Report on a ten year study of a tooth division technique for the removal of impacted teeth. Am J Orthod Oral Surg 1942; 28:B660-6. doi: 10.1016/S00966347(42)90021-8.

[11] K. Carter et al. Predictors of Third Molar Impaction: A Systematic Review and Metaanalysis. Journal of Dental Research; 1-10 doi: 10.1177/0022034515615857

[12] Reddy KVG, Prasad KVV. Prevalence of third molar impactions in urban population of age 22-30 years in South India: An epidemological study. J Indian Dent Assoc 2011; 5:609-11.

[13] Haidar Z, ShalhoubSY.The incidence of impacted wisdom teeth in a Saudi community. Int J Oral MaxillofacSurg 1986; 15:569-71. doi: 10.1016/S0300-9785(86)80060-6.

[14] Hassan AH. Pattern of third molar impaction in a Saudi population. ClinCosmetInvestig Dent 2010; 2:109-13. doi:10.2147/CCIDEN.S12394.

[15] Quek SL, Tay CK, Tay KH, Toh SL, Lim KC. Pattern of third molar impaction in a Singapore Chinese population: A retrospective radiographic survey. Int J Oral MaxillofacSurg 2003; 32:548-52. doi: 10.1016/S09015027(03)90413-9.
[16] Samira M. Al-Anqudi et al. Prevalence and Pattern of Third Molar Impaction A retrospective study of radiographs in Oman. Sultan Qaboos University Med J, August 2014. pp. e388-392

[17] Sandhu S, KaurT.Radiographic evaluation of the status of third molars in the Asian-Indian students. J Oral MaxillofacSurg 2005; 63:640-5. doi: 10.1016/j.joms.2004.12.014.

[18] Monaco G, Montevecchi M, Bonetti GA, Gatto MR, Checchi L. Reliability of panoramic radiography in evaluating the topographic relationship between the mandibular canal and impacted third molars. J Am Dent Assoc. 2004;135:312-8.

[19] Obiechina AE, Arotiba JT, Fasola AO. Third molar impaction: evaluation of the symptoms and pattern of impaction of mandibular third molar teeth in Nigerians. Odontostomatol Trop. 2001;24:22-5.

[20] Rajasuo A, Murtomaa H, Meurman JH. Comparison of the clini $\neg$ cal status of third molars of young men in 1949 and in 1990.Oral Surg Oral Med Oral Pathol. 1993;76:694-8.

[21] Almendros-Marqués N, Berini-Aytés L, GayEscoda C. Influ ence of lower third molar position on the incidence of preoperative complications. Oral Surg Oral Med Oral Pathol Oral RadiolEndod. 2006;102:725-32.

Citation: Altaf Hussain Chalkoo, Bashir Ahmad Wani, Shazia Maqbool, Tauseefa Jan, Rayees Ahmad Sheikh. Pattern of Third Molar Impaction in Kashmiri Population. ARC Journal of Dental Science. 2020; 5(3):8-13. DOI: https://doi.org/10.20431/2456-0030.0503003.

Copyright: (C) 2020 Authors. This is an open-access article distributed under the terms of the Creative Commons Attribution License, which permits unrestricted use, distribution, and reproduction in any medium, provided the original author and source are credited. 